\title{
NMR study of surfactant molecules intercalated in montmorillonite and in silylated montmorillonite
}

\author{
J. GRANDJEAN ${ }^{1, *}$, J. BUJDÁK ${ }^{2}$ AND P. KOMADEL ${ }^{2}$ \\ ${ }^{1}$ University of Liege, Institute of Chemistry B6a, COSM, Sart Tilman, B-4000 Liege, Belgium, and ${ }^{2}$ Institute of \\ Inorganic Chemistry, Slovak Academy of Sciences, Bratislava, SK-842 36, Slovak Republic
}

(Received 1 October 2002; revised 20 February 2003)

\begin{abstract}
C}$ CP MAS NMR and ${ }^{29} \mathrm{Si}$ MAS NMR were used to characterize silylated montmorillonites and to estimate the extent of the silylation reaction. Indirectly-detected proton relaxation times of the intercalated surfactant were measured in both silylated and non-silylated clay systems to monitor the dynamics of intercalated species. A greater degree of mobility in the silylated montmorillonites was found. The lack of NMR information resulting from paramagnetic interaction brought about by structural $\mathrm{Fe}$ (III) ions was considered. The resulting broadening can prevent the estimation of the trans/gauche conformer ratio of the intercalated surfactant alkyl chain.
\end{abstract}

KEYwords: 2:1 phyllosilicate, montmorillonite, ${ }^{13} \mathrm{C}$ CP MAS, ${ }^{29} \mathrm{Si}$ CP MAS NMR.

Polymers are commonly admixed with a variety of both natural and synthetic compounds to improve their performance. Nanocomposites constitute a new class of materials with an ultrafine phase dispersion (e.g. clay), of the order of a few nm, which endows them with unique properties not shared by conventional materials and which offers new technological and economic opportunities (Zanetti et al., 2000). To obtain clay-polymer nanocomposites, one of the critical steps in their preparation using modified clays is the surface treatment of the mineral. Cationic surfactants substitute for interlamellar cations to form intercalated clay-surfactant hybrids. The surface treatment is to ensure the dispersion of the mineral within the polymer matrix.

Clay characteristics should affect the structure and dynamics of the intercalated molecules and play a role in the properties of the final nanocomposite. These systems are currently characterized by the $d_{001}$ basal spacing which may be

* E-mail: j.grandjean@ulg.ac.be

DOI: $10.1180 / 0009855033830103$ related indirectly to the number of surfactant layer(s) and their mean orientation with respect to the mineral basal plane (Lagaly, 1986; Dékány et al., 1986a,b,c; Dékány \& Nagy, 1991). Such structures are almost exclusively based on alltrans configuration of the alkyl chain. This assumption is not very appropriate since the energy difference between trans and gauche conformers is rather small $(\sim 2.5 \mathrm{~kJ} / \mathrm{mol}$, Flory, 1953). Fourier transform infrared spectroscopy (FT-IR) provides a more direct means by which to define the surfactant molecule orientation and conformation. These results are based on small variations of vibrational frequencies assigned to stretching and bending modes of the methylene $\left(\mathrm{CH}_{2}\right)$ groups (Vaia et al., 1994).

Nuclear magnetic resonance (NMR) is known to be a powerful technique for probing structure, conformation and dynamics of molecules at interfaces (Grandjean, 1998, 2002). Magic angle spinning (MAS) NMR has been used to characterize clay structure (Dékány et al., 1999), and a few NMR studies have been reported on modified 
laponite (Kubies et al., 2002) and montmorillonites (Wang et al., 2000; VanderHart et al., 2001a). Detailed data analysis leading to dynamic and conformational information requires the absence of paramagnetic species as found with synthetic clay minerals (Kubies et al., 2002). Natural clays, montmorillonites in particular, are usually used as raw material for preparation of polymer nanocomposites. Unfortunately, $\mathrm{Fe}(\mathrm{III})$, a paramagnetic cation, substitutes partly for $\mathrm{Al}$ (III) in the octahedral sheet, and even in small amounts may give rise to paramagnetic interaction that can perturb the NMR parameters (VanderHart et al., 2001a). Nevertheless, polymer nanocomposites prepared with these modified clays have been studied by NMR methods (VanderHart et al., 2001b).

In this paper, the prepared modified clays were first characterized by NMR. Then, the effect of silylation of montmorillonite particle edges on the behaviour of intercalated surfactant molecules was studied using NMR relaxation parameters. As this montmorillonite contains paramagnetic Fe(III) cations, we have also defined how NMR provides valuable information compared to similar studies on non paramagnetic systems (Kubies et al., 2002).

\section{MATERIALS AND METHODS}

\section{Materials}

Montmorillonite from Southern Clay Products, Inc. (Texas) has properties as described in the literature; in particular about one tenth of octahedral sites is substituted by paramagnetic ferric ions (VanderHart et al., 2001a), corresponding to an $\mathrm{Fe}_{2} \mathrm{O}_{3}$ content of $\sim 3.5$ wt. \% . The $\mathrm{Na}^{+}$smectite (S) was obtained by an exchange process (Bujdák et al., 2002). Its cation exchange capacity (CEC) was determined to be $0.95 \pm 0.02 \mathrm{mmol} / \mathrm{g}$ by ionexchange with alkylammonium cations. Addition of dodecyltriethoxysilane $\mathrm{CH}_{3}-\left(\mathrm{CH}_{2}\right)_{11}-\mathrm{Si}-$ $\left(\mathrm{OCH}_{2} \mathrm{CH}_{3}\right)_{3}$ (DDS) or tridecafluoro-1,1,2,2,-tetrahydrotrimethoxysilane $\mathrm{CF}_{3}-\left(\mathrm{CF}_{2}\right)_{5}-\left(\mathrm{CH}_{2}\right)_{2}-$ $\mathrm{Si}-\left(\mathrm{OCH}_{3}\right)_{3}$ (FS) to the clay suspensions led to silylation of the clay particle edges. Details of the preparation and isolation of the final products are described in the literature (Bujdák et al., 2002). Self-condensation of such silylating agents is known, forming dimers, trimers or higher-order aggregates. However, the experimental conditions used do not favour this process (Bujdák et al., 2002). Self-condensation (if any) at neutral $\mathrm{pH}$ is much slower in ethanol with the small amount of water brought to the system by adding the clay. The $\mathrm{Si}-\mathrm{OH}$ groups at the clay particle edges are already in activated form before the activation of silane takes place, and the reaction occurs preferentially with clay particle edges, due to their basicity, resulting from hydrolysis of octahedral sheets. Several tests were performed to prove the silylation of the clay particle edges (Bujdák et al., 2002). Clay silylation with monoethoxy (forming only dimers as self-condensation products) and triethoxysilane derivatives provides materials with quite similar characteristics (XRD, IR, etc.). The small amount of attached silane, although an excess of reactant was used, is not consonant with bound aggregates which should also lead to extra lines in the ${ }^{29} \mathrm{Si}$ NMR spectrum. The amount of organosilanes attached is $\sim 0.10 \mathrm{mmol} / \mathrm{g}$. The interlayer distance obtained from XRD remained unchanged after silylation (1.32 and $1.31 \mathrm{~nm}$ for FS and DDS, respectively). Furthermore, after ion-exchange with octadecylammonium (ODA) or octadecyltrimethylammonium (ODTA) cations, the $d_{001}$ basal values were 1.81 and $1.85 \mathrm{~nm}$ for ODA-FS-S and ODTADDS-S, respectively (Bujdák et al., 2002). These values are not affected by silylation reaction, and are similar to those reported by Wang et al. (2000) and Kubies et al. (2002), probably corresponding to a bilayer of organic cations lying down on the silicate surface (Török et al., 2000).

\section{NMR spectra}

${ }^{29} \mathrm{Si}$ and ${ }^{13} \mathrm{C}$ NMR spectra were recorded with $4 \mathrm{~mm}$ zirconia rotors on a Bruker Avance ${ }^{\circledR}$ DSX $400 \mathrm{WB}$ spectrometer $\left(B_{0}=9.04 \mathrm{~T}\right)$ working at the Larmor frequency of 79.50 and $100.62 \mathrm{MHz}$, respectively. The ${ }^{13} \mathrm{C}$ CP MAS (Cross-Polarization Magic Angle Spinning) spectra of silylated and non-silylated modified montmorillonites were run with 300,000 scans under high-power proton decoupling $(83 \mathrm{kHz})$ with a delay time of $50 \mathrm{~ms}$, and a contact time of $0.1 \mathrm{~ms}$. A rather high spinning rate of $9 \mathrm{kHz}$ was used to avoid spinning side bands which would prevent the analysis of the sample composition. The basic cross-polarization (CP) technique used here is more efficient at slower spinning rate, and the relaxation-time measurements were performed at $4 \mathrm{kHz}$. Increasing the contact time, the signal intensity first increases as protonheteronucleus dipolar interaction builds up until optimal cross-polarization, then decreases when 
proton relaxation in the rotating frame $\left(T_{1 \rho}(\mathrm{H})\right)$ becomes dominant. This usual behaviour is not observed here, the intensity remaining practically constant in the 0.005-0.3 ms range, as an effect of paramagnetic interaction or non two-spin systems (Kolodzejski \& Klinowski, 2002). The carbondetected proton relaxation times $T_{1}(\mathrm{H})$ and $T_{1 \rho}(\mathrm{H})$ were determined by varying the proton interpulse delay and the duration of the ${ }^{1} \mathrm{H}$ spin-lock period, respectively, before a fixed contact period, and detection of the heteronuclear spin with proton decoupling. The relaxation times $T_{1 \rho}(\mathrm{C})$ were measured from the signal decay in the presence of ${ }^{13} \mathrm{C}$ irradiation after the contact period, and detection with proton decoupling. All of the parameters were optimized, and the ${ }^{13} \mathrm{C}$ resolution was checked on a glycine sample (signal-to-noise $(\mathrm{S} / \mathrm{N}) \geqslant 50$ for the methylene signal). The experiments (12-16 delays) were run with 30,000 scans. The single pulse $(5.5 \mu \mathrm{s}){ }^{29} \mathrm{Si}$ MAS NMR spectra were acquired with 60,000 scans at a spinning rate of $5 \mathrm{kHz}$. All the experiments were performed at room temperature (294 K).

\section{RESULTS AND DISCUSSION ${ }^{13} C N M R$}

By contrast with methods used previously to characterize such modified clays (Bujdák et al., 2002), ${ }^{13}$ C CP MAS NMR provides a direct means by which to study the silylation reaction. The relevant ${ }^{13} \mathrm{C}$ chemical shifts are summarized in Table 1.
TABLE 1. Relevant ${ }^{13} \mathrm{C}$ and ${ }^{29} \mathrm{Si}$ chemical shifts $\delta$ (ppm relative to TMS).

\begin{tabular}{lclr}
\hline Nucleus & $\delta$ & Nucleus & $\delta$ \\
\hline $\mathrm{Si}-\mathrm{CH}_{2}$ & 2.9 & $\mathbf{C H}_{2}(\mathrm{DDS})$ & 30 \\
$\mathbf{C H}_{3}(\mathrm{ODA})$ & 16 & $\mathrm{CH}_{2}(\mathrm{ODA})$ & 32 \\
$\mathrm{O}_{-} \mathrm{CH}_{2}-\mathrm{CH}_{3}$ & 20 & $\mathbf{S i}\left(\mathrm{Q}_{3}\right)$ & -94 \\
$\mathrm{Si}-\mathrm{CH}_{2}-\mathbf{C H}_{2}$ & 26 & $\mathbf{S i}\left(\mathrm{T}_{3}\right)$ & -71 \\
& & & \\
\hline
\end{tabular}

The ${ }^{13} \mathrm{C}$ CP MAS NMR spectrum of the silylated montmorillonite (FS-S) exhibits two signals, at 2.9 and $26 \mathrm{ppm}$, of equal intensity, assigned to the $\alpha$ and $\beta \mathrm{CH}_{2}$ groups relative to the $\mathrm{Si}$ nucleus, respectively (Fig. 1).

Most methoxy groups of the tridecafluoro-1,1,2,2,tetrahydrotrimethoxysilane $\mathrm{CF}_{3}-\left(\mathrm{CF}_{2}\right)_{5}-\left(\mathrm{CH}_{2}\right)_{2}-\mathrm{Si}-$ $\left(\mathrm{OCH}_{3}\right)_{3}$ (FS) have reacted, as no signal near $50 \mathrm{ppm}$ (Joseph et al., 1996) is observed. The fluorinated carbons that are not enhanced by crosspolarization give intensity signals which are too weak to be detected under these experimental conditions. Montmorillonite silylation with dodecyltriethoxysilane (DDS) gives a product (DDS-S) the ${ }^{13} \mathrm{C}$ CP MAS NMR spectrum of which exhibits a small signal observed at $\sim 56 \mathrm{ppm}$ (Fig. 1) assigned to the methylene group of $-\mathrm{SiOCH}_{2} \mathrm{CH}_{3}$ (Joseph et al., 1996), indicating incomplete reaction of the starting organosilane with the edges of the clay. The main signal of most $\mathrm{CH}_{2}$ groups is found at $\sim 30 \mathrm{ppm}$ with an upfield shoulder in the $0-25$ ppm range. The latter contains the resonances
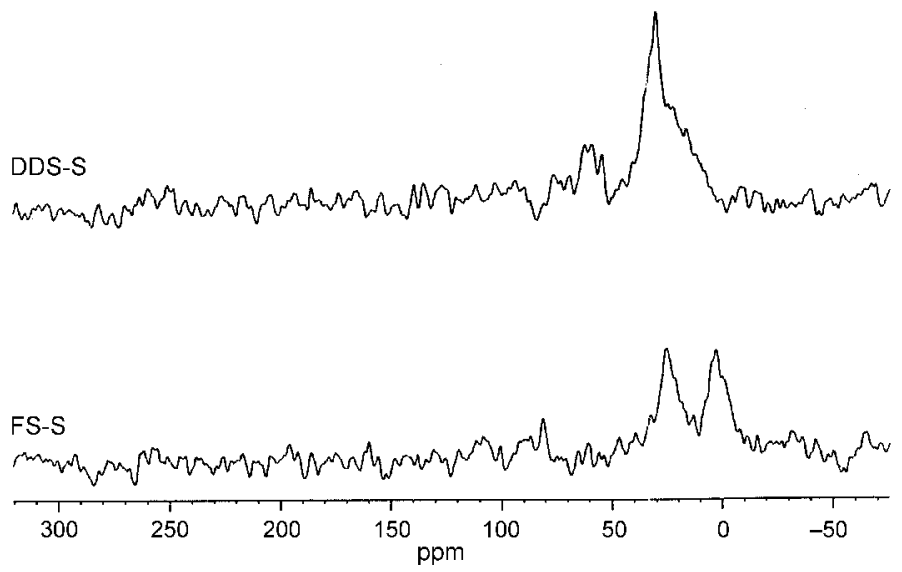

FIG. $1 .{ }^{13} \mathrm{C}$ CP MAS NMR spectra of silylated montmorillonites DDS-S and FS-S. 


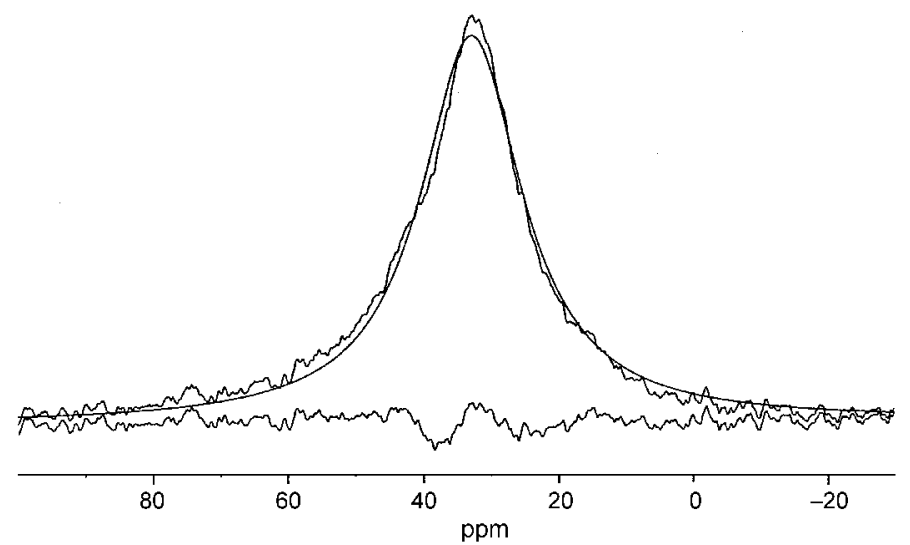

FIG. 2. Experimental, simulated (smooth line) and difference (bottom line) ${ }^{13} \mathrm{C} \mathrm{CP}$ MAS NMR spectra of ODA-S.

of the terminal methyl group of the dodecyl chain, the two methylene groups close to the silicon nucleus (see above) together with the residual methyl signal of $\mathrm{OSiCH}_{2} \mathrm{CH}_{3}$. Although these spectra are not fully quantitative, an estimation of the reaction yield can be made from band integration. The intensities of the $56 \mathrm{ppm}$ and the main asymmetric signals are $\sim 0.5$ and 2.4 , respectively. After subtraction of the amount for the deconvoluted $\mathrm{OSiCH}_{2} \mathrm{CH}_{3}$ methyl signal, near $20 \mathrm{ppm}$ (Joseph et al., 1996), the main signal intensity is $\sim 1.9$. Assuming no silylation reaction, 0.5 integration units corresponds to 3 carbon nuclei, and 1.9 to $\sim 12$ carbon nuclei. That means only partial silylation, with, at most, reaction of one ethoxysilane group per DDS molecule, on average.

The ${ }^{13} \mathrm{C}$ CP MAS NMR spectra of the surfactantexchanged clays (ODA-S and ODTA-S) are characterized by a main signal in the $34-31 \mathrm{ppm}$ range attributed to $\mathrm{CH}_{2}$ groups (Wang et al., 2000; Kubies et al., 2002). Such a signal mainly consists of two resolved resonances, depicting the trans and gauche conformations of the $\mathrm{CH}_{2}$ groups, when the exchanged clay contains no paramagnetic atoms as in the case of laponite (Kubies et al., 2002). Paramagnetic interaction can broaden the lines to such an extent that the experimental signal can be simulated with a simple broad Lorentzian curve, as with the clay minerals used in the present study (Fig. 2). Thus, information on the trans/gauche conformation ratio is lost. Furthermore, the position of the peak can be changed slightly by paramagnetic interaction, and the mean chemical shift cannot be used to estimate the dominant conformer. However, as the line broadening depends on the ferric ion concentration, in modified montmorillonites with lower paramagnetic content, the trans/ gauche ratio can still be estimated (Wang et al., 2000). The silylated clays have also been exchanged with cationic surfactants (ODA-FS-S and ODTA-DDS-S). The ${ }^{13} \mathrm{C}$ CP MAS NMR spectrum of the ODA-FS-S compound shows one main signal at $\sim 32 \mathrm{ppm}$ with a very small signal at $16 \mathrm{ppm}$, assigned to the surfactant methyl group (data not shown). The contribution of the $25.5 \mathrm{ppm}$ signal of the silylated clay mineral to the signal of the surfactant methylene groups is negligible since no signal is observed at $2.9 \mathrm{ppm}$. The weak signal at $56 \mathrm{ppm}$ for the ODTA-DDS-S sample indicates a small contribution $(<10 \%)$ of the $30 \mathrm{ppm}$ signal of DDS to the $32 \mathrm{ppm}$ signal of ODTA. This is consistent with the surfactant amount, larger by one order of magnitude than that of the fixed silane.

\section{${ }^{29} \mathrm{Si} N M R$}

The ${ }^{29} \mathrm{Si}$ MAS NMR spectrum of the silylated montmorillonite (FS-S) shows two signals at -94 and $-71 \mathrm{ppm}$ (Fig. 3). The first signal is assigned to the silicate group $\left(\mathrm{Q}_{3}\right.$ type) (Sanz \& Robert, 1992). The other signal from the bound fluorosilane is less intense by one order of magnitude, in agreement with chemical analysis. Its chemical shift is also consistent with reaction of most methoxy groups of the starting material $\left(\mathrm{T}_{3}\right.$ type, Joseph et al., 1996). After intercalation of ODA, the amplitude of this signal is strongly reduced (data not shown). Assuming constant silylation, restriction of the chain mobility can broaden the signal accounting for this observation. Silylation reaction 


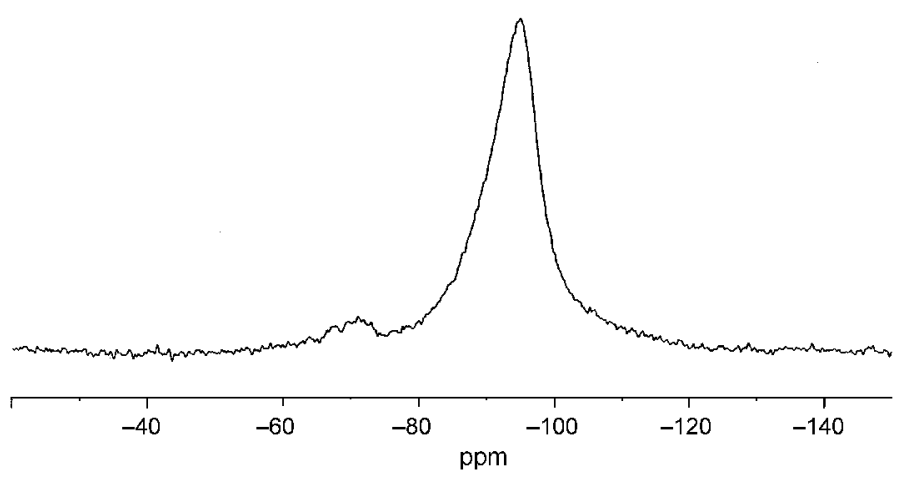

FIG. 3. ${ }^{29}$ Si MAS NMR spectrum of FS-S.

with DDS was incomplete as indicated by ${ }^{13} \mathrm{C}$ NMR data. This is supported by a very weak ${ }^{29} \mathrm{Si}$ NMR signal centred at $\sim-63 \mathrm{ppm}$. Greater hydrophobicity of FS leads to larger amounts of anchored silane derivatives (Bujdák et al., 2002). Thus, aggregation of the starting compounds should differ, giving rise to different reactivity, but further study is required to prove it.

\section{Relaxation times}

As structural Fe (III) ions (modified clays were prepared from Na-exchanged phyllosilicate, eliminating possible exchangeable paramagnetic cations) are at the midplane of the $\sim 1 \mathrm{~nm}$ thick montmorillonite layer, the protons of the intercalated surfactant can be in the $0.5-1 \mathrm{~nm}$ range from the paramagnetic ions. Such protons can experience both a direct line broadening (with a signal loss) and a shortening of the relaxation times, resulting from electron-electron spin-exchange between different $\mathrm{Fe}$ (III) ions. Local field fluctuation responsible for these effects originates from the different dipolar couplings of the two exchanging electron spins and the nuclear spin of the proton considered (VanderHart et al., 2001a).

The carbon-13 detected proton relaxation times in the laboratory frame $T_{1}(\mathrm{H})$ and in the rotatory frame $T_{1 \rho}(\mathrm{H})$ are summarized in Table 2. These values are one order of magnitude less than those obtained in laponite systems (Kubies et al., 2002), showing a strong paramagnetic effect.

The values obtained with ODA-S and ODTA-S (Table 2) agree with those reported in the literature, supporting a similar ferric ion content (VanderHart et al., 2001a). All the $T_{1 \rho}(\mathrm{H})$ plots show some deviation from single-exponential behaviour as an effect of a distribution of $T_{1 \rho}(\mathrm{H})$ values due to a range of proton-paramagnetic centre distances and different electron-nuclear dipole-dipole interaction (VanderHart et al., 2001a). This paramagnetic effect generally precludes a detailed analysis of intercalated species. However, comparison between systems with the same paramagnetic content as here with the two series of modified smectites, remains valid. The relaxation times of the surfactant methylene group are systematically larger with the silylated compounds (Table 2). Such a difference cannot be explained by variation of the paramagnetic interaction. Indeed, the interlayer separation is not affected by silylation, and the mean protonelectron $(\mathrm{Fe}(\mathrm{III}))$ distance remains unchanged leading to constant paramagnetic effect. The observed differences can be explained by a change in segment mobility of the intercalated surfactant or by an increase of the dipolar interaction resulting from additional proton (or fluorine) nuclei. As the line shape is influenced by silylation, that points unambiguously to a

TABLE 2. ${ }^{13} \mathrm{C}$ and proton relaxation times of the $\mathrm{CH}_{2}$ groups in the laboratory frame $\left(T_{1}(\mathrm{H})\right)$ and in the rotatory frame $\left(T_{1 \rho}(\mathrm{H})\right)$ of the $\mathrm{CH}_{2}$ groups of octadecylammonium (ODA) and octadecyltrimethylammonium (ODTA) cations intercalated in montmorillonite (S) and silylated montmorillonites (S-FS or SDDS). Data from Kubies et al. (2002) are given in parentheses.

\begin{tabular}{llcl} 
Sample & $T_{1}(\mathrm{H}) \mathrm{ms}$ & $T_{1 \rho}(\mathrm{H}) \mu \mathrm{s}$ & $T_{1 \rho}(\mathrm{C}) \mathrm{ms}$ \\
& & & \\
ODA-S & $4.98(66.1)$ & $91.8(3700)$ & $1.06(7.69)$ \\
ODA-S-FS & 8.63 & 213 & 2.07 \\
ODTA-S & 5.09 & 101 & 1.12 \\
ODTA-S-DDS & 7.64 & 157 & 1.54 \\
\hline
\end{tabular}


dynamic effect. Molecular dynamics modulate NMR relaxation times which are measured, after the perturbation brought by radio frequency pulses, with or without a continuous radio frequency field $\left(T_{1 \rho}(\mathrm{H})\right.$ and $T_{1}(\mathrm{H})$, respectively). These two relaxation times sample different mobility ranges, and are often measured indirectly from the observation of the heteronucleus $\left({ }^{13} \mathrm{C}\right.$ or ${ }^{29} \mathrm{Si}$ NMR). The larger chemical shift range of the heteronuclear nucleus provides a better spectrum resolution. These results are corroborated by the measurements of $T_{1 \rho}(\mathrm{C})$ relaxation times (Table 2).

Silylation reaction of the clay particle edges with hydrophobic silane derivatives gives rise to larger clay particle aggregates (stacks) due to edge-toedge cohesion forces (Bujdák et al., 2002). The increase in relaxation times and the line-narrowing upon silylation (Table 2) account for faster motion of the intercalated species (Kubies et al., 2002). The enhancement ratio is smaller with ODTA-SDDS than with ODA-S-FS, in agreement with a smaller reaction yield, and reduced edge-to-edge cohesion forces in the ODTA-S-DDS system with respect to the ODA-S-FS system.

\section{CONCLUSIONS}

The products resulting from montmorillonite silylation have been characterized by ${ }^{13} \mathrm{C}$ CP MAS NMR and ${ }^{29} \mathrm{Si}$ MAS NMR. The ${ }^{13} \mathrm{C}$ NMR signals in the $50-60 \mathrm{ppm}$ range are particularly useful for describing the extension of the silylation reaction. The presence of paramagnetic ions such as structural $\mathrm{Fe}(\mathrm{III})$ can prevent detailed analysis. Thus, when about one tenth of the octahedral sites are occupied by ferric ions, line broadening does not resolve peaks from the trans and gauche conformers. On the other hand, paramagnetic interaction interferes drastically in the nuclear relaxation process, and information on molecular dynamics are only obtained by comparison of smectites with identical paramagnetic ion content. We have shown that silylation of montmorillonite gives rise to mobility increase of intercalated surfactant molecules.

\section{ACKNOWLEDGMENTS}

J.G. thanks the Belgian "Fonds National de la Recherche Scientifique" for a grant to purchase the solid-state NMR spectrometer and for financial support of this research (Grant 2.4503.02). J.G. and P.K. are grateful for support in the collaboration frame "Wallonia-Slovakia". The financial support of the Slovak Grant Agency VEGA (Grant 2/7202) is also acknowledged.

\section{REFERENCES}

Bujdák J., Iyi N. \& Fujita T. (2002) The aggregation of methylene blue in montmorillonite dispersions. Clay Minerals, 37, 121-133.

Dékány I. \& Nagy L.G. (1991) Immersional wetting and adsorption displacement on hydrophilic/hydrophobic surfaces. Journal of Colloid and Interface Science, 147, $119-127$.

Dékány I., Szántó F., Weiss A. \& Lagaly G. (1986a) Interactions of hydrophobic layer silicates with alcohol-benzene mixtures. I. Adsorption isotherms. Berichte der Bunsengesellschaft der Physikalische Chemie, 90, $422-427$.

Dékány I., Szántó F., Weiss A. \& Lagaly G. (1986b) Interactions of hydrophobic layer silicates with alcohol-benzene mixtures. II. Structure and composition of the adsorption layer. Berichte der Bunsengesellschaft der Physikalische Chemie, 90, $427-431$.

Dékány I., Szántó F. \& Nagy L.G. (1986c) Sorption and immersional wetting on clay minerals having modified surface. II. Interlamellar sorption and wetting on organic montmorillonites. Journal of Colloid and Interface Science, 109, 376-384.

Dékány I., Turi L., Fonseca A. \& Nagy J.B. (1999) The structure of acid treated sepiolites: Small-angle $\mathrm{X}$-ray scattering and multi MAS-NMR investigations. Applied Clay Science, 14, 141-160.

Flory P.J. (1953) Principles of Polymer Chemistry, pp. 399-431. Cornell University Press, Ithaca, New York.

Grandjean J. (1998) NMR study of interfacial phenomena. Annual Reports on NMR Spectroscopy, 35, $217-260$.

Grandjean J. (2002) Nuclear magnetic resonance spectroscopy of molecules and ions at clay surfaces. Pp. 3700-3712 in: Encyclopedia of Surfaces and Colloid Science (A.T. Hubbard, editor). Marcel Dekker, New York.

Joseph R., Zhang, S. \& Ford W.T. (1996) Structure and dynamics of a colloidal silica-poly(methylmethacrylate) composite by ${ }^{13} \mathrm{C}$ and ${ }^{29} \mathrm{Si}$ MAS NMR. Macromolecules, 29, $1305-1312$.

Kolodzejski W. \& Klinowski J. (2002) Kinetics of crosspolarization in solid-state NMR: A guide for chemists. Chemical Review, 102, 613-628.

Kubies D., Jérôme R. \& Grandjean J. (2002) Surfactant molecules intercalated in laponite as studied by ${ }^{13} \mathrm{C}$ and ${ }^{29} \mathrm{Si}$ MAS NMR. Langmuir, 18, 6159-6163. 
Lagaly G. (1986) Interaction of alkylamines with different types of layered compounds. Solid States Ionics, 22, $43-51$.

Sanz J. \& Robert J.-L. (1992) Influence of structural factors on ${ }^{29} \mathrm{Si}$ and ${ }^{27} \mathrm{Al}$ NMR chemical shifts of phyllosilicates 2:1. Physics and Chemistry of Minerals, 19, 39-45.

Török B., Bazázsik K., Dékány I. \& Bartók M. (2000) Preparation and characterization of new chirally modified laponites. Molecular Crystals and Liquid Crystals, 341, 339-344.

Vaia R.A., Teukolsky R.K. \& Giannelis E.P. (1994) Interlayer structure and molecular environment of alkylammonium layered silicates. Chemistry of Materials, 6, $1017-1022$.

VanderHart D.L., Asano A. \& Gilman J.W. (2001a) Solid-state NMR investigation of paramagnetic nylon-6 clay nanocomposites. 1. Crystallinity, mor- phology, and the direct influence of $\mathrm{Fe}^{3+}$ ions on nuclear spins. Chemistry of Materials, 13, $3781-3795$.

VanderHart D.L., Asano A. \& Gilman J.W. (2001b) Solid-state NMR investigation of paramagnetic nylon-6 clay nanocomposites. 2. Measurement of clay dispersion, crystal stratification, and stability of organic modifiers. Chemistry of Materials, 13, $3796-3809$.

Wang L.-Q., Liu J., Exarhos G.J., Flanigan K.Y. \& Bordia R. (2000) Conformation heterogeneity and mobility of surfactant molecules in intercalated clay minerals studied by solid-state NMR. Journal of Physical Chemistry B, 104, 2810-2816.

Zanetti M., Lomakin S. \& Camino G. (2000) Polymer layered silicate nanocomposites. Macromolecular Materials and Engineering, 279, 1-9. 